\title{
ENERGY EFFICIENT AUTO-CONFIGURABLE ALGORITHM FOR WIRELESS SENSOR NETWORKS
}

\author{
Mohammad Rokon Uddin * Mohammad Abdul Matin ${ }^{* *}$ \\ Mohammad Kamal Hossain Foraji ${ }^{*}$ - Baizid Hossain *
}

\begin{abstract}
This paper proposed an auto-configurable algorithm for wireless sensor network (WSN) to efficiently re-organize the network topology. The auto-configurable algorithm is based on self- configurable cellular architecture and it has been observed from simulation result that the proposed algorithm achieves lower power consumption than the existing one.

K e y w o r d s: wireless sensor network, auto-configuration, self-configuring algorithms, topology control
\end{abstract}

\section{INTRODUCTION}

In recent days, wireless sensor network has become a greater interest in the application of disaster management, border protection, battle field security surveillance, monitor microclimates and wildlife habitats, the structural integrity of bridges and buildings, building security, location of valuable assets, traffic, and so on. WSNs are composed of heterogeneous or homogeneous sensor devices. These devices are called sensor nodes (SNs) which have limited battery energy, memory, and computational power. SNs are self-operated ie operated autonomously in unattended or remote environments. For this reason, wireless sensor networks need to be self or auto configured without prior knowledge about the network architecture [1-4].

The architecture presented in [5] for WSN suffers few difficulties such as cell formation (clustering), splitting, and merging. Subramanian and Katz provided network architecture based on heterogeneity of sensor nodes [6]. However, this hierarchical architecture is not possible to deploy SNs in all type of WSNs especially in cases where there are lots of cut nodes. G. Gupta and M. Younis [7] proposed load-balanced clustering for WSN where the gateway node acts as a cell manager and if it fails, the cluster will dissolved, and all of its nodes are re-allocated to other healthy gateways. J. L. Chen et al [8] proposed hierarchical self-organizing architecture follows "20/80 rule" to resolve the ratio of cluster heads and member nodes. But again re-clustering is not energy efficient in this architecture. G. Venkataraman et al [9] proposed a self- organizing sensor network in which new cell manager is selected based on the energy and request message exchange procedures. But this is very time and energy consuming. M. Asim et al $[10,11]$ proposed a selfconfiguration hierarchical network architecture which is based on homogeneity of sensor nodes. However, it consumes more energy in case of failure of the cell manager.
In this paper, we have proposed an auto-configurable architecture for WSNs based on cellular approach which is energy efficient in case of failure of the cell manager or cluster head.

\section{FAULT MANAGEMENT AND SELF-CONFIGURING APPROACHES}

There are several approaches for self-configuring wireless sensor network and it is reconfigured in such a way that the changes won't affect the whole network operation and performance. There are many fault management architectures. For examples, S. Marti et al [12] proposed that if there is a failure of a neighbouring node in the WSN architecture, a new neighbouring node would be selected for routing. F. Koushanfar et al [13], suggested a heterogeneous backup procedure. This procedure is for curing the hardware malfunctioning of a sensor node. According to their proposal a single type of hardware can provide backup to different types of resources. But this solution is not directly related to fault healing in respect of M. Yu, H. Mokhtar, and M. Merabti's [14] discussion about network system level management. In G. Gupta and M. Younis [15] proposed fault-tolerant clustering, when the gateway node fails, the cluster suspended and all of its nodes are re-allocated to other healthy gateways which consumes more time because of the involvement of all the cluster nodes in the recovery process. Ruiz et al [16] proposed a malfunction detection method where a management architecture for WSNs is suggested named MANNA. In this approach, an external manager is required for performing centralized diagnosis and communication between nodes. This external manager is expensive for sensor networks. W. L. Lee et al [17] proposed a proactive fault management system, where the central manager detects areas with low residual energy ie weak network health by comparing the current node or network

${ }^{*}$ Department of Electrical Engineering and Computer Science, North South University, Dhaka, Bangladesh ${ }^{* *}$ Department of Electrical and Electronic Engineering, Institut Teknologi Brunei, Brunei Darussalam, m.a.matin@ieee.org 


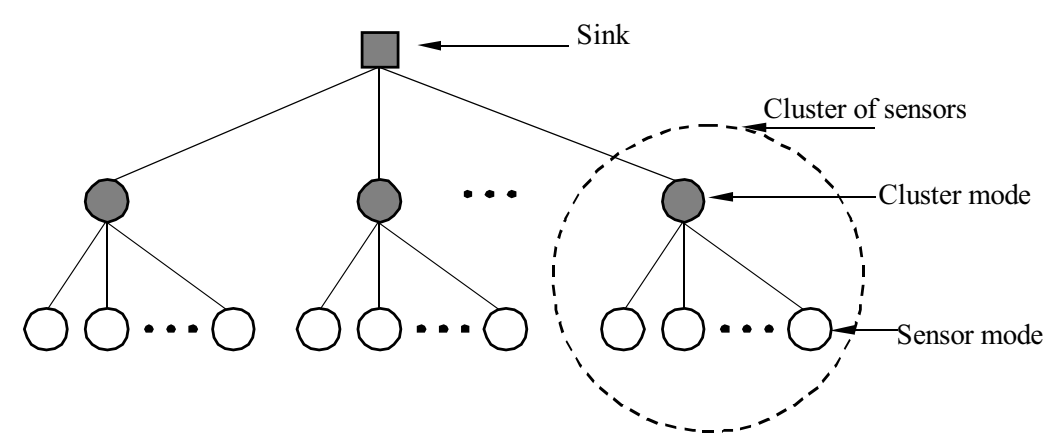

Fig. 1. Cluster based hierarchical network for sensor networks

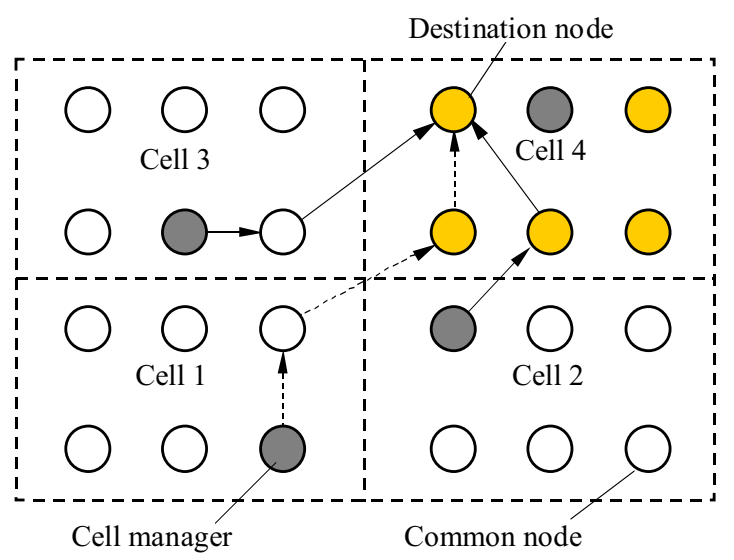

Fig. 2. Cluster merging process

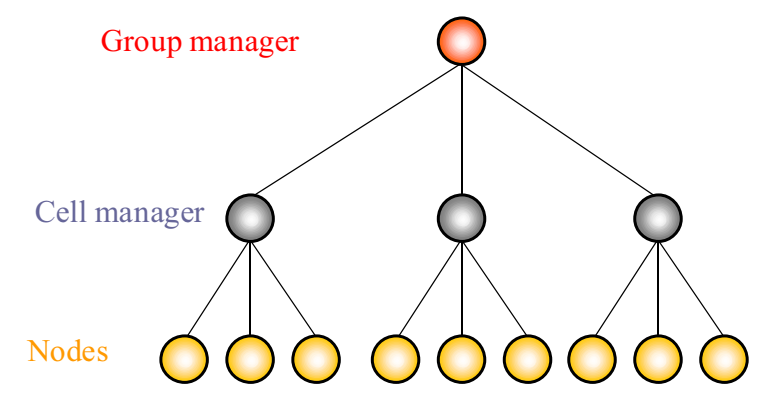

Fig. 3. Cellular hierarchical network architecture for wireless sensor networks

state with the historical network information model (eg energy map and topology map). It proactively instructs the nodes of that area to send data less frequently. Luo et al [18] proposed an algorithm to improve the failure event detection precision in the existence of faulty sensor nodes. Their algorithm did not unambiguously attempt to identify faulty sensor nodes. Krishnamachari and Iyengar [19] proposed localized threshold based decision schemes for detecting misbehaving sensor nodes and happening areas. Some authors suggested some routing techniques to identify the faulty or misbehaving sensor nodes [20-22]. After studying these algorithms and fault management approaches, we come up with an energy efficient selfconfiguring solution for WSNs. It does not consume more energy in case of the failure of a cell manager or cluster head.

\subsection{Autonomic Algorithm}

Autonomic algorithm for WSN is a three tier hierarchical network management system as shown in Fig. 1. The higher level nodes are called headers and low level nodes are called member nodes. The header nodes may cause the member nodes to be clustered in hostile environments. The headers nodes broadcast 'cover request' message periodically $[23,24]$. If a cluster head down to low residual battery energy, the member nodes select a cluster head based on minimum hop count value by flooding the network with 'cover request' messages. If a header node die or deplete its energy then all its cluster members have to select and join a new header based on minimum hop count value. For example, we can consider a scenario like Fig. 2, there are 4 clusters and cluster 4 header is no longer available to perform its regular operations. So member need to join a new cluster header. Cluster 1, 2, and 3 header will send 'cover request' messages to all the members of cluster 4 . Based on the minimum hop count value, cluster 4 members will select a new cluster head from neighbouring clusters for themselves. Say, nodes of cluster 4 are going to join cluster 1 header due to minimum hop count. But cluster 1 header has low residual energy and need to go sleep.

This scenario initiates the re-configuration phase again as all the member nodes of cluster head 4 and cluster 1 required a new cluster head to perform their regular operations. For this reason, considering only hop count value is not energy efficient procedure in case of cluster head selection [10].

\subsection{Existing Self-configuring Algorithm}

In self-configuring wireless sensor network, sensor nodes are in a virtual grid structure in which the network nodes are divided into several cells. One node in each cell is selected as cell manager. Upper level nodes of the grid are cell managers and the remaining nodes will be in lower level grid. A large virtual group can be formed by several virtual cells and these cells can have hundreds to thousands sensor nodes. A group manager is appointed for each virtual group. This group manager is 


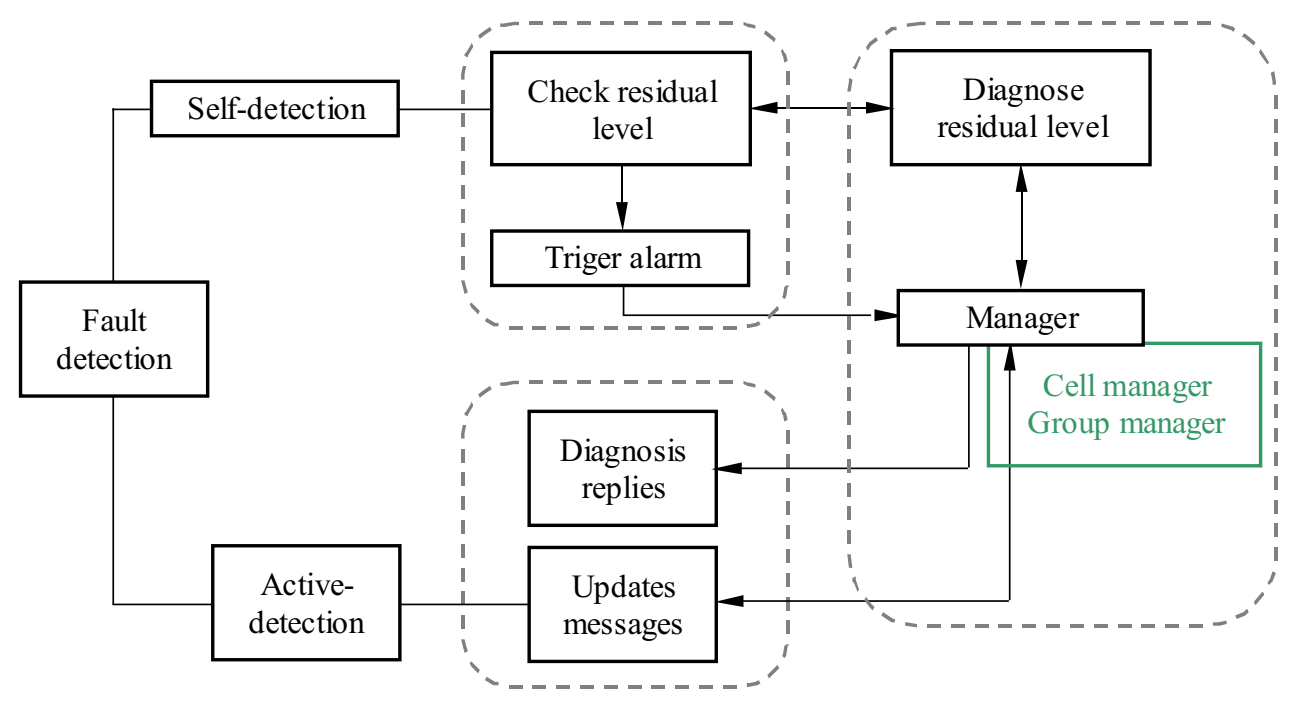

Fig. 4. Fault detection and diagnosis process

responsible for managing and organizing sensor nodes in its group. Another virtual grid structure is created by the group managers from different groups. This structure is shown in Fig. 3. The next to the management hierarchy is the sink which is above the group manager.

In this paper, we are referring the algorithm of $\mathrm{M}$. Asim et al [10] as existing algorithm. This self-configuring algorithm follows cellular approach $[25,26]$. In self-detection mechanism, sensor nodes monitor their residual battery energy periodically to identify the probable failure. M. Asim et al consider the reduction of battery energy as a main cause of sensor node's sudden death. A sensor node is considered as a failing node when its battery energy drops below the threshold value. When a member node is failing due to low battery energy, it sends message to its cell manager about the low battery energy and goes to sleep mode. Member node failure does not require any recovery.

The self-configuring algorithm considers active-detection mode for efficient detection of the sensor node's sudden death. In active-detection mechanism, cell manager asks its member nodes to send their updates regularly. To get the updated status of the member nodes, the cell manager exchange messages with its member nodes which is shown in Fig. 4. The cell manager sends "get" messages to its member nodes on regular basis. The member nodes reply with their updates. This update method is called in-cell update cycle. This update message (update msg) consists of node ID, battery energy and node's location information. If such scenario happens where the cell manager is not receiving any update message from one of its member node, the cell manager sends an instant message to that node. If the cell manager does not get any acknowledgement message in a defined time, it affirms the node as faulty. Then the cell manager sends this information to the member nodes in its cell. If the performance of the network is in a critical level only then the cell managers inform the group manager to get further assistance.
In the existing algorithm, there is a secondary cell manager as backup of the cell manager. When a cell manager's residual battery energy becomes low, secondary cell manager takes the role of the cell manager and chooses a new secondary cell manager from the energy update messages which are being sent periodically by the member nodes [11]. When there is no node to take the role of the cell manager in that cell, cell merging procedure will start.

\subsection{Proposed Algorithm}

In the existing self-configuring algorithm, when the residual energy of both the cell manager and secondary cell manager are less than or equal to $20 \%$, the member nodes exchange energy messages within the cell to appoint a new cell manager. It consumes high energy. We are proposing a modification to minimize this energy consumption. In our algorithm, there is no secondary cell manager. In case of low residual energy of the cell manager, cell manager will select the next high energy node and appoint as new cell manager from the energy list which is being periodically updated from the messages sent by the member nodes i.e. there will be no exchange of energy messages within the cell when the residual energy of both the cell manager and secondary cell manager are low. It will consume less energy. A member node should have greater or equal to $50 \%$ of its residual battery energy for being appointed as cell manager. If there is no node (residual battery energy is greater or equal to $50 \%$ ) to take cell manager's responsibility in that cell, cell merging activity will take place like the existing selfconfiguring algorithm. In this algorithm, we are not considering the highest energy node as new cell manager but the next higher energy node for avoiding sorting mechanism because a WSN of thousands of nodes will take higher energy and time for sorting the energy list. A flow chart of our proposed algorithm is presented in Fig. 5. 


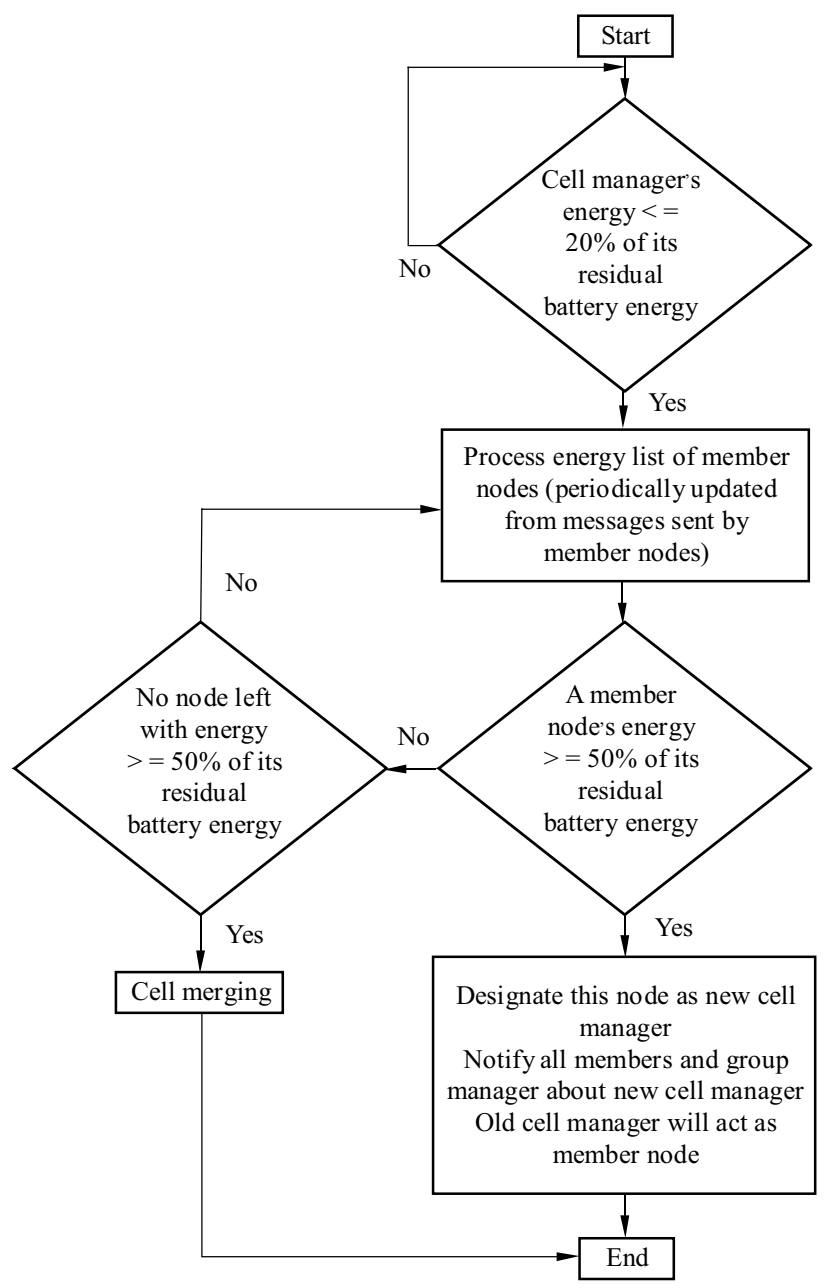

Fig. 5. Flow chart for proposed algorithm

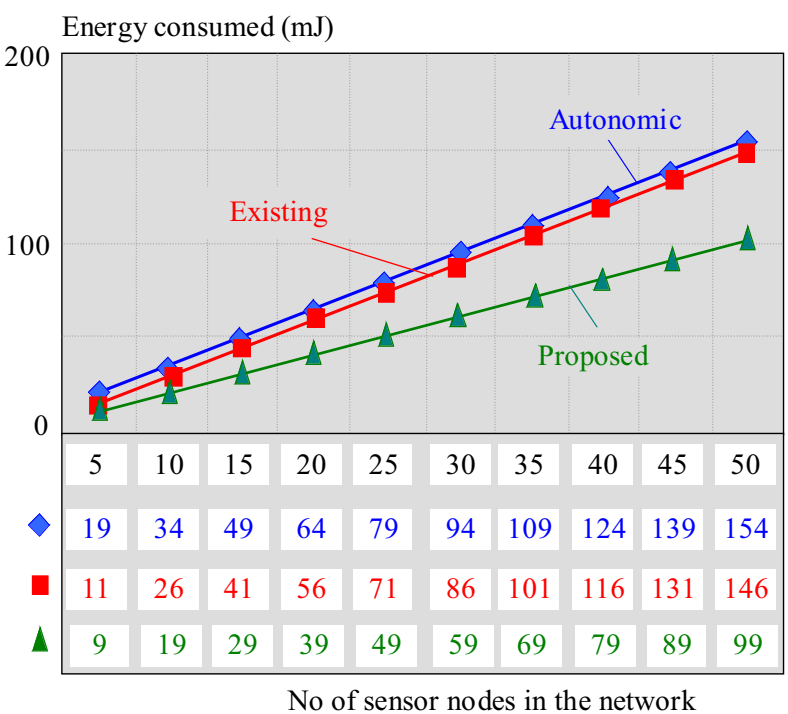

Fig. 6. Comparison of Autonomic, Existing and Proposed algorithm for self-configuring WSN

\section{PERFORMANCE EVALUATION}

The performance of the proposed algorithm evaluated using our developed simulator and analyzed to measure node energy expenditure which is given in Fig. 6. Number of sensors is varied from 5 to 50 . Each sensor is assumed to have an initial energy of $2000 \mathrm{~mJ}$.

In autonomic algorithm, the cluster head could be failed to operate due to insufficient residual energy and all the sensor nodes from that cluster need to join with a neighbouring cluster head using cluster merging technique Cluster merging is not an energy efficient process to re-organize the clusters and also time consuming in compare to our proposed algorithm.

In the existing self-configuring algorithm, when a cell manager's residual battery energy becomes low, secondary cell manager takes the role of the cell manager and chooses a new secondary cell manager from the energy update messages which are being sent periodically by the member nodes.

If the residual energy of both cell manager and secondary cell manager are low, the member nodes exchange energy messages within the cell and choose new cell manager. The new cell manager again selects a new secondary cell manager. The condition for being a cell manager is to have greater than or equal to $50 \%$ of its residual battery energy. This consumes high energy. If there is no node to take the role of the cell manager, cell merging technique will happen. 
In the proposed algorithm, there will be no secondary cell manager. Every cell manager has the updated list of energy status of its member nodes. If a cell manager's residual battery energy becomes low, it will designate the next high energy node from the list as the new cell manager (having energy greater or equal to $50 \%$ of its residual energy). This process will continue till there are nodes having energy greater than or equal to $50 \%$ of its residual energy in case of failure of the cell manager. This process will consume less energy.

\section{CONCLUSIONS}

Wireless sensor networks are a collection of heterogeneous or homogeneous sensor devices that have limited battery energy, memory and computational power. Sensor node failure due to limited battery energy interrupts the operation of WSN. To keep the network operation uninterrupted and smooth, self-configuring techniques are imposed in WSN. In this paper, an energy efficient modified algorithm for wireless sensor network has been proposed based on the existing self-configuring algorithm. The proposed algorithm can select a suitable sensor node to be a cell manager to reorganize the topology more efficiently and reduce the power consumption.

\section{REFERENCES}

[1] BHARATHIDASAN, A.-ANAND, V.: Sensor Networks: An overview, 2002, Technical Report CA 95616.

[2] AKYILDIZ, I. F.-SU,-SANKARASUBRAMANIAM, Y.CAYIRCI, E. : A Survey on Sensor Networks, IEEE Communication Magazine (2002), 102-114.

[3] LEWIS, F.: Wireless Sensor Networks, Smart Environments: Technology, Protocols and Applications, Wiley-InterScience, 2002.

[4] LEE, W. L.-DATTA, A.-CARDELL-OLIVER, R. : Network Management in Wireless Sensor Networks Handbook of Mobile, Ad Hoc and Pervasive Communications, American Scientific Publishers, 2006.

[5] RAMANATHAN, R.-STEEnSTRUP, M.: Hierarchically Organized, Multihop Mobile Wireless Networks for Quality-of-Service Support, ACM/Baltzer Mobile Networks and Applications, vol 101-119, 1998

[6] SUBRAMANIAN, L.-KATZ, R. H.: An Architecture for Building Self-Configurable Systems, Proceeding of the IEEE/ ACM Workshop on Mobile Ad Hoc Networking and Computing (MobiHOC 2000), 2000, pp. 63-73.

[7] GUPTA, G.-YOUNIS, M. : Load-Balanced Clustering in Wireless Sensor Networks, Proceedings of International Conference on Communication (ICC 2003), Anchorage, AK, 2003.

[8] CHEN, J. L.-LU, H. F.-LEE, C. A.: Autonomic Self-Organization Architecture for Wireless Sensor Communications, International Journal of Network Management 17 (2007), 197-208.

[9] VENKATARAMAN, G.-EMMANUEL, S.-THAMBIPILLAI, S.: Energy-Efficient Cluster-Based Scheme for Failure Management in Sensor Networks, IET Communications 2 (2008), 528-537.

[10] ASIM, M.-MOKHTAR, H.-MERABTI, M. : A Self-Managing Fault Management Mechanism for Wireless Sensor Networks,
International Journal of Wireless \& Mobile Networks (IJWMN) 2 No. 4 (2010), 184-197.

[11] ASIM, M.-YU, M.-MOKHTAR, H.-MERABTI, M.: A Self-Configurable Architecture for Wireless Sensor Networks, 2010 Developments in E-systems Engineering, pp. 76-81.

12] MARTI, S.-GIULI, T. J.-LAI, K.-BAKER, M. : Mitigating Routing Misbehaviour in Mobile Ad Hoc Networks, ACM Mobicom (2000), 255-265.

[13] KOUSHANFAR, F.-POTKONJAK, M.-SANGIOVANNI VINCENTELLI, A.: Fault Tolerance Techniques in Wireless Ad-Hoc Sensor Networks, UC Berkeley technical reports.

[14] YU, M.-MOKHTAR, H.-MERABTI, M. : A survey on Fault Management in Wireless Sensor Network, Proceedings of the 8th Annual Postgraduate Symposium on the Convergence of Telecommunications, Networking and Broadcasting Liverpool, UK, 2007.

[15] GUPTA, G.-YOUNIS, M. : Fault-Tolerant Clustering of Wireless Sensor Networks, Proceedings of the IEEE WCNC 2003, New Orleans, Louisiana, 2003.

16] RUIZ, L. B.-SIQUEIRA, I. G.-OLIVEIRA, L. B.-WONG, H. C.-NOGUEIRA, J. M. S.-LOUREIRO, A. A. F. : Fault Management in Event-Driven Wireless Sensor Networks, Proc. 7th ACM Int. Symp. Modeling, Analysis and Simulation of Wireless and Mobile Systems, Venice, Italy, pp. : 149-156.

17] LEE, W. L.-DATTA, A.-CARDELL-OLIVER, R. : WinMS: Wireless Sensor Network-Management System, An Adaptive Policy-Based Management for Wireless Sensor Networks, School of Computer Science and Software Engineering, The University of Western Australia, 2006, Technical Report, UWA-CSSE-06-01.

[18] LUO, X.-XDONG, V-HUANG, Y.: On Distributed FaultTolerant Detection in Wireless Sensor Networks, Proc. IEEE Trans. Comput. 55 No. 1, 58-70.

[19] KRISHNAMACHARI, B.-IYENGAR, S. : Distributed Bayesian Algorithms for Fault-Tolerant Event Region Detection in Wireless Sensor Network, IEEE Trans. Comput. 53 No. 3, $241-250$.

[20] STADDON, J.-BALFAnZ, D.—DURFEE, G. : Efficient Tracing of Failed Nodes in Sensor Networks, Proc. 1st ACM Int. Workshop on Wireless Sensor Networks and Applications, Atlanta, USA, Sep 2002, pp. 122-130.

[21] TANACHAIWIWAT, S.-DAVE, P.-BHINDWALE, R.HELMY, A. : Secure Locations: Routing on Trust and Isolating Compromised Sensors in Location-Aware Sensor Networks, Proc. 1st Int. Conf. Embedded Networked Sensor Systems, Los Angeles, Nov 2003, pp. 324-325.

[22] PERRIG, A.-SZEWCZYK, R.-WEN, V.-CULLER, D. E. -TYGAR, J. D.: SPINS: Security Protocols for Sensor Networks, Proc. Wirel. Netw. 8 No. 5, 521-534.

[23] ABBASI, A. A.-YOUNIS, M.: A Survey on Clustering Algorithms for Wireless Sensor Networks, Computer Communications 30 (2007), 2826-2841.

[24] DECHENE, D. J.-JARDALI, A. E.-LUCCINI, M.-SAUER, A.: A Survey of Clustering Algorithms for Wireless Sensor Networks, 2006, Project Report.

[25] ASIM, M.-MOKHTAR, H.-MERABTI, M.: A Cellular Self-Organization Architecture for Wireless Sensor Networks, PG NET 2008 Liverpool.

[26] ASIM, M.-MOKHTAR, H.-MERABTI, M.: A Cellular Approach to Fault Detection and Recovery in Wireless Sensor Networks, The Third International Conference on Sensor Technologies and Applications SENSORCOMM 2009 Greece, pp. 352-357.

Received 5 February 2012 